\title{
Healing of erosions in rheumatoid arthritis
}

\author{
Tuulikki Sokka, Pekka Hannonen
}

\begin{abstract}
Reports on healing of erosions in rheumatoid arthritis are rare. However, it is expected that repair of erosions should be seen more often during the period of extensive use of disease modifying antirheumatic drugs, especially in patients who experience sustained remission. Two such cases are described. (Ann Rheum Dis 2000;59:647-649)
\end{abstract}

Bone erosions in joints have generally been considered as irreversible end state changes in rheumatoid arthritis (RA). Accordingly, reports on healing of erosions are rare. In the cases described here, joint repair was associated with suppression of inflammation. ${ }^{1-4}$ During the period of more extensive use of disease modifying antirheumatic drugs (DMARDs), especially during clinical remission, healing of erosions can be expected to be seen more frequently. Here we describe two cases with such a phenomenon.

\section{Case reports}

PATIENT 1

A 27 year old car mechanic had tenderness in his feet in summer 1991. June 1992 he was admitted to our rheumatology clinic owing to morning stiffness, tenderness, and swelling in the small joints of his hands and feet, which had lasted for four months. Rheumatoid factor was positive, erythrocyte sedimentation rate (ESR) $25 \mathrm{~mm} / 1 \mathrm{st} \mathrm{h}$, and $\mathrm{C}$ reactive protein (CRP) $8 \mathrm{mg} / 1$. A Larsen grade $2^{5}$ erosion was seen only in the left fifth metatarsophalangeal (MTP) joint. The disease met the American College of Rheumatology Criteria (ACR-87) for RA. ${ }^{6}$ DMARD treatment was started with sulfasalazine $2 \mathrm{~g}$ daily. Six months later the patient was in clinical remission. In June 1994 he discontinued sulfasalazine because he had no symptoms of RA. Three months later, however, the symptoms returned, and sulfasalazine was restarted.

In April 1995 he was admitted to the clinic with a flare of RA. ESR was $41 \mathrm{~mm} / 1 \mathrm{st} \mathrm{h}$ and CRP $27 \mathrm{mg} / 1$. Radiographic examination showed erosions in several MTP joints. Intramuscular (IM) gold was added to the sulfasalazine. Nevertheless, his RA remained active.

In February 1996, his ESR was $80 \mathrm{~mm} / 1 \mathrm{st} \mathrm{h}$, CRP $62 \mathrm{mg} / \mathrm{l}$, and erosions in the MTP joints had increased. IM gold was replaced by methotrexate $10 \mathrm{mg}$ weekly, and sulfasalazine was continued. During the following months, the weekly dose of methotrexate was increased to 20 mg. During 1997 he went into remission
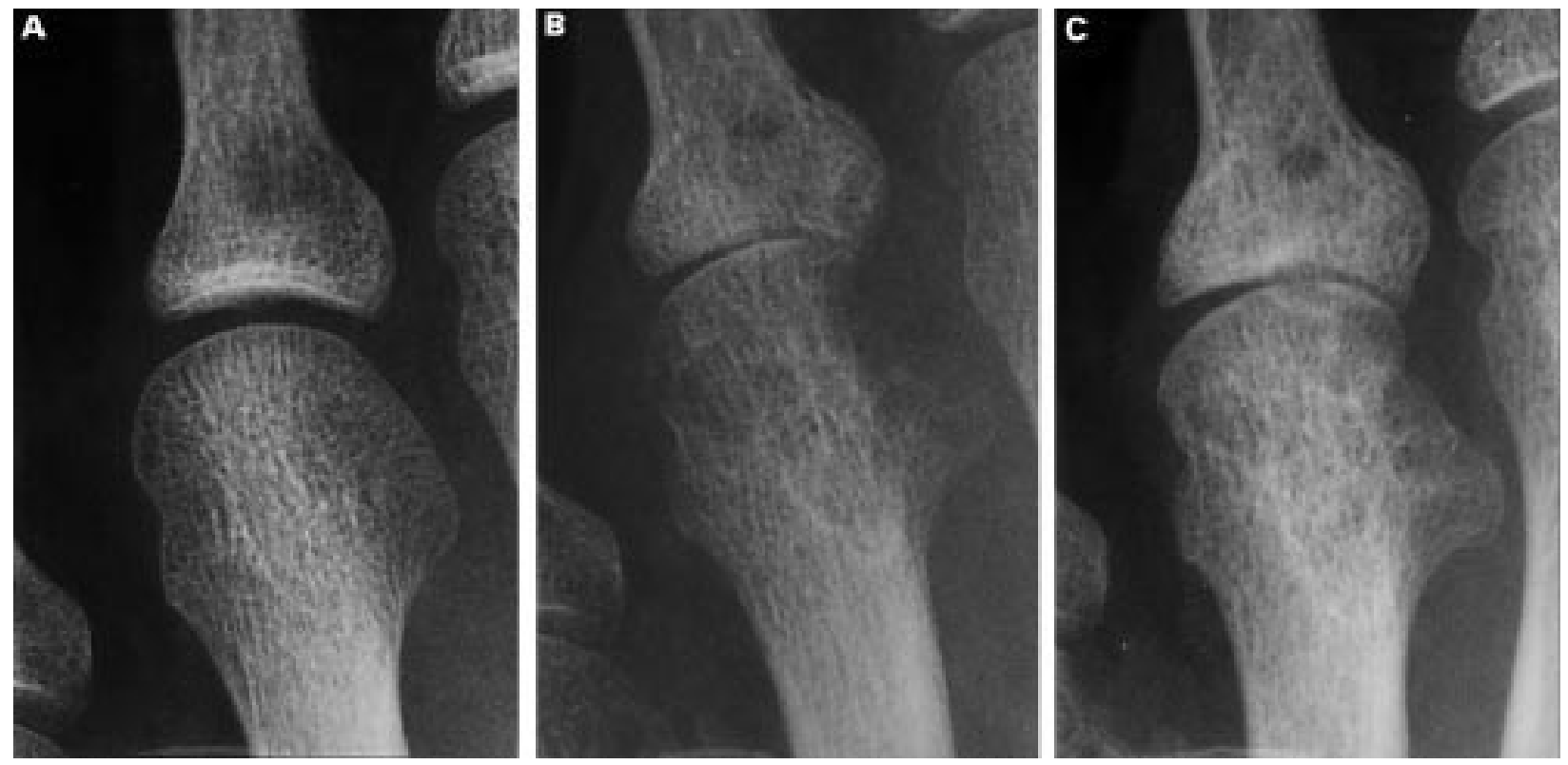

Figure 1 (A-C) Development of erosive changes in the left fourth metatarsophalangeal joint of patient 1. In fune 1992 (A) the joint was normal, in April 1995 (B) erosive changes had developed, and in March 1999 (C) the erosion was filled with new bone with recortication. 

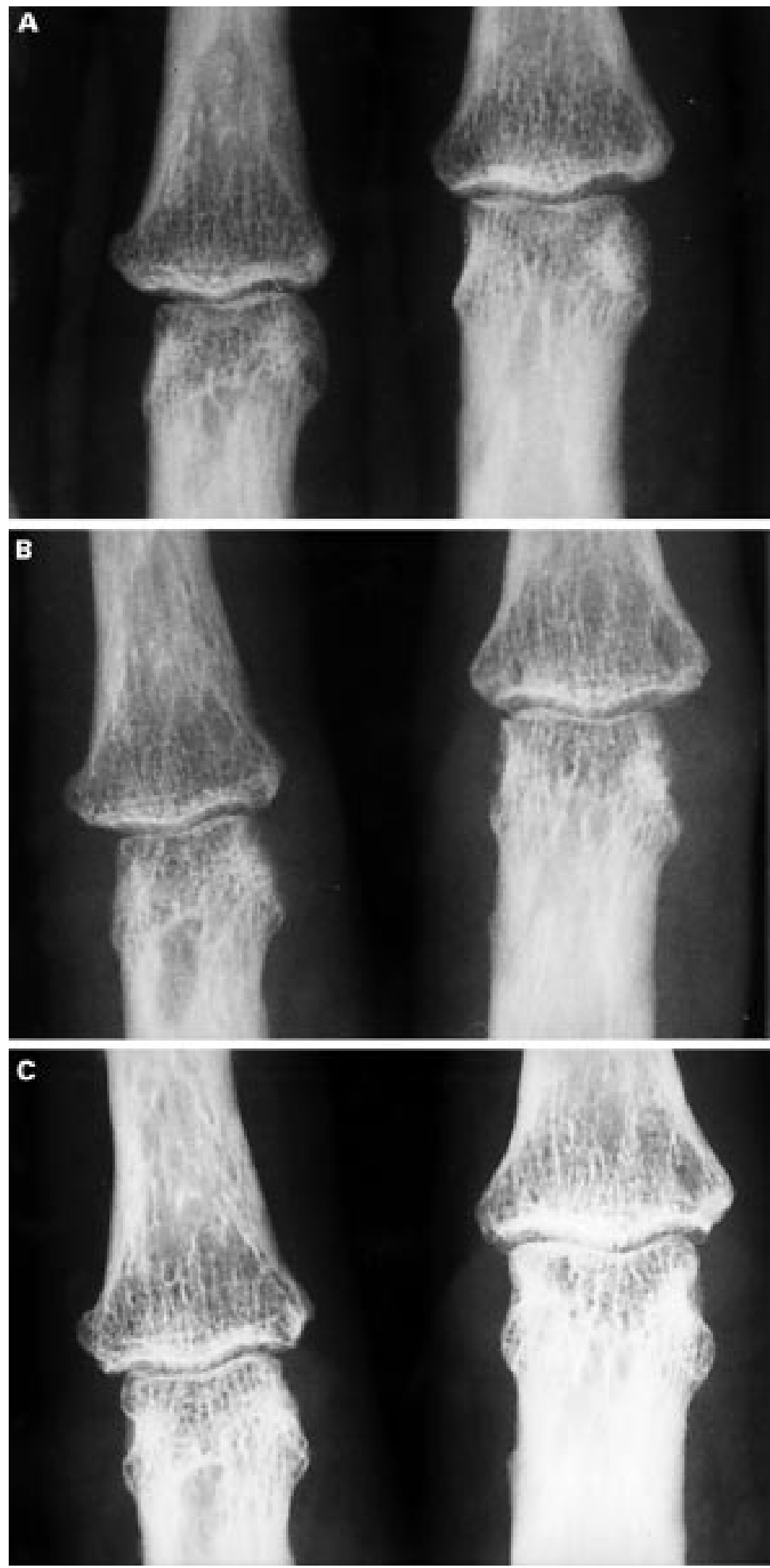

Figure 2 ( $A-C)$ Left third and fourth proximal interphalangeal joints of patient 2. At the time of diagnosis in April 1989 (A) no erosions were seen, in April 1990 (B) the cortex of the heads of the proximal phalanges of the joints had disappeared on the left and right side, but remained on the top. In fanuary 1997 (C) no active erosions were seen, but recortication had taken place. The shapes of the heads of the proximal phalanxes remained changed.

and was still in remission by March 1999, when no tender or swollen joints were found, ESR was $11 \mathrm{~mm} / 1 \mathrm{st} \mathrm{h}$, and CRP $5 \mathrm{mg} / \mathrm{l}$. Healing of MTP erosions was recorded (fig 1). The patient has never been treated with systemic or local glucocorticoids.
PATIENT 2

Palindromic $\mathrm{RA}^{7}$ of a 49 year old woman became chronic in the joints of the hands, feet, and knees in March 1989. She met the ACR-87 criteria for seronegative RA. In June 1989 her ESR was $44 \mathrm{~mm} / 1 \mathrm{st} \mathrm{h}$, CRP $46 \mathrm{mg} / \mathrm{l}$, and no erosions in radiographs of the hands and feet were found. Both knees and second to fifth proximal interphalangeal (PIP) joints in both hands were tender and swollen, whereas only tenderness was recorded in both feet. IM gold treatment was started. In three months the patient developed allergic dermatitits, and IM gold was replaced by auranofin. In January 1990 she was in clinical remission with no swollen or tender joints; her ESR was $6 \mathrm{~mm} / 1 \mathrm{st}$ h. However, in April 1990 erosions of the PIP joints were seen in plain radiographs. Auranofin was discontinued in August 1993 owing to clinical remission, continuing still in May 1997. The erosive changes in the PIP joints had healed (fig 2). Systemic or local glucocorticoids were not used.

\section{Discussion}

Healing of erosive changes in RA includes formation of new bone, recortication of erosions, and secondary osteoarthrosis. ${ }^{1}$ Healing of erosions is associated with disappearance of inflammation in the joints affected, and with complete clinical remission of RA in most cases. Rau and Herborn described six, ${ }^{1}$ and McCarty and Carrera nine patients ${ }^{2}$ who had been treated with IM gold or combinations of DMARDs, while in other patients whose erosions had been repaired, methotrexate or IM gold has been used. ${ }^{3}$ Controlled clinical trials show that several individual DMARDs, ${ }^{8}$ or their combinations, ${ }^{9}{ }^{10}$ slow the progression of erosions in RA in the short term, and some longitudinal observational studies indicate that the use of DMARDs can retard progression of radiographic joint damage in $\mathrm{RA}$ also in the long term. ${ }^{811-13}$ Preliminary, so far unpublished, reports of the anti-erosive efficacy of biological treatments are also promising. ${ }^{14-16}$ Until now, however, reports on healing of erosions have been rare (more extensively discussed in reference ${ }^{1}$ ). None the less, reports on this phenomenon ought to re-encourage rheumatologists to treat their patients with RA with all available DMARDs to the point of "no evidence of disease" ${ }^{17}$ rather than to tolerate signs of disease activity.

Longitudinal observations of clinical patients offer a better opportunity to study healing in RA than do short term clinical trials. However, to document healing, patients must be assessed regularly and radiographs taken also during clinical remission. We regard this healing phenomenon as a hopeful sign for the rheumatology community in the fight against RA.

1 Rau R, Herborn G. Healing phenomena of erosive changes in rheumatoid arthritis patients undergoing diseasemodifying antirheumatic drug therapy. Arthritis Rheum 1996;39:162-8.

2 McCarty DJ, Carrera GF. Intractable rheumatoid arthritis. Treatment with combined cyclophosphamide, azathioprine, and hydroxychloroquine. JAMA 1982;248:1718-23. 
3 Jalava S, Reunanen K. Healing of erosions in rheumatoid

4 Weinblatt ME, Trentham DE, Fraser PA, Holdsworth DE, Falchuk KR, Weissman BN, et al. Long-term prospective Falchuk $\mathrm{KR}$, Weissman $\mathrm{BN}$, et al. Long-term prospective trial of low-dose methotrexate in
Arthritis Rheum 1988;31:167-75.

Arthritis Rheum 1988;31:167-75.
5 Larsen A, Dale K, Eek M. Radiographic evaluation of rheumatoid arthritis and related conditions by standard reference films. Acta Radiol Diagn 1977;18:481-91.

6 Arnett FC, Edworthy SM, Bloch DA, McShane DJ, Frie $\mathrm{JF}$, Cooper NS, et al. The American Rheumatism Association 1987 revised criteria for the classification of rheumatoid arthritis. Arthritis Rheum 1988;31:315-24.

7 Hannonen P, Möttönen T, Oka M. Palindromic rheumatism. A clinical survey of sixty patients. Scand J Rheumatol 1987;16:416-20.

8 Sokka T, Kaarela K, Möttönen T, Hannonen P. Conventional monotherapy compared to 'sawtooth' treatment strategy in the radiographic progression of rheumatoid strategy in the radiographic progression of rheumatoid 1999;17:527-32.

9 Boers M, Verhoeven AC, Markusse HM, van de Laar MA Westhovens R, van Denderen JC, et al. Randomized comparison of combined step-down prednisolone, methotrexate and sulphasalazine with sulphasalazine alone in early rheumatoid arthritis. Lancet 1997;350:309-18

10 Möttönen T, Hannonen P, Leirisalo-Repo M, Nissilä $M$, Kautiainen $\mathrm{H}$, Korpela $\mathrm{M}$, et al. Comparison of combination therapy with single-drug therapy in early rheumatoid arthritis: a randomised trial. Lancet 1999;356:1568-73.
11 Luukkainen R, Isomäki H, Kajander A. Effect of gold treatment on the progression of erosions in RA patients. Scand Rheumatol 1977;6:123-7.

12 Möttönen T, Paimela L, Ahonen J, Helve T. Hannonen P, Leirisalo-Repo M. Outcome in patients with early rheumatoid arthritis treated according to the "sawtooth" strategy. Arthritis Rheum 1996;39:996-1005.

13 Abu-Shakra M, Toker R, Flusser D, Flusser G, Friger M, Sukenik S, et al. Clinical and radiographic outcomes of rheumatoid arthritis patients not treated with diseasemodifying drugs. Arthritis Rheum 1998;41:1190-5.

14 Finck B, Martin R, Fleischmann R, Moreland L, Schiff M, J Bathon. A phase III trial of etanercept vs methotrexate (mtx) in early rheumatoid arthritis (Enbrel ERA Trial) [abstract]. Arthritis Rheum 1999;42:S117.

15 Rau R, Herborn G, Sander O, van de Putte LBA, van Riel PLC, den Broeder A, et al. Long-term treatment with the fully human anti-TNF-antibody D2E7 slows radiographic disease progression in rheumatoid arthritis [abstract]. Arthritis Rheum 1999;42:S400

16 Lipsky P, Clair W St, Furst D, Breedveld F, Smolen J, Kalden JR, et al. 54-week clinical and radiographic results from the ATTRACT trial: a phase III study of infliximab (Remicade) in patients with active RA despite methotrexate cade) in patients with active RA despite
[abstract]. Arthritis Rheum 1999;42:S401.

17 Pincus T, Wolfe F, Stein C. 'No evidence of disease' in rheumatoid arthritis using methotrexate in combination with other drugs: a contemporary goal for rheumatology care? Clin Exp Rheumatol 1997;15:591-6. 